\title{
El raloxifeno reduce el riesgo de fractura vertebral en mujeres con osteoporosis
}

Reduction of Vertebral Fracture Risk in Postmenopausal Women With Osteoporosis Treated With Raloxifene. Results From a 3 - Years

Randomized Clinical Trial. Ettinger B, Black DM, Mitlak BH. JAMA. 1999;282:637-645.

\section{Objetivo}

Determinar si el tratamiento con raloxifeno tiene efecto sobre el riesgo de fracturas vertebrales y no vertebrales en mujeres postmenopáusicas con osteoporosis.

\section{Diseño}

Estudio multicéntrico, doble ciego, aleatorizado, con tres años de seguimiento.

\section{Lugar}

Se realizó en 180 centros en 25 países de todo el mundo (aproximadamente la mitad en Estados Unidos y Canadá).

\section{Pacientes}

Se evaluaron 7705 mujeres con menopausia de por lo menos dos años de duración, entre 31 y 80 años. El $95.7 \%$ eran de raza blanca, con diagnóstico de osteoporosis definida por densidad mineral ósea baja (según los criterios de OMS) o fracturas vertebrales visibles en las radiografías. Se excluyeron a las mujeres que padecían enfermedades graves o tratamientos recientes con drogas que afectaran el metabolismo óseo.

\section{Intervención}

Las pacientes recibieron en forma aleatorizada $60 \mathrm{mg}$ ó $120 \mathrm{mg}$ de raloxifeno o placebo una vez por día. A su vez, todas las pacientes recibieron diariamente $500 \mathrm{mg}$ de calcio y 400-600 UI de colecalciferol. AL inicio del estudio se dividió a las pacientes en dos grupos, en base a la existencia de fracturas vertebrales previas.

\section{Mediciones de resultados principales}

Se determinaron las fracturas vertebrales por radiografías al iniciar el estudio y a los 24 y 36 meses. La densidad mineral ósea se midió anualmente.

\section{Resultados principales}

El seguimiento fue de alrededor del $90 \%$ para evaluar fracturas ( 6828 mujeres). El raloxifeno redujo el riesgo de fracturas vertebrales a ambas dosis. Esta reducción se observó en ambos grupos de mujeres

Fuente de financiamiento: Eli Lilly and Company, Indianapolis, Ind. (con o sin fractura previa). En el grupo de mujeres sin fractura previa, ambas dosis de raloxifeno fueron similares, mientras que en las mujeres con fracturas previas la dosis de $120 \mathrm{mg}$ fue algo mejor. (ver tabla)

Resultados: fracturas vertebrales

\begin{tabular}{|c|c|c|c|c|c|}
\hline \multirow[t]{2}{*}{ Variable } & \multicolumn{2}{|c|}{$\begin{array}{l}\text { Mujeres sin } \\
\text { fracturas previas }\end{array}$} & \multicolumn{3}{|c|}{ Mujeres con fracturas previas } \\
\hline & $\begin{array}{l}\text { Placebo } \\
(n=1522)\end{array}$ & $\begin{array}{r}\text { Raloxifeno } \\
(\mathrm{n}=3002)\end{array}$ & $\begin{array}{l}\text { Placebo } \\
(n=770)\end{array}$ & $\begin{array}{l}\text { Raloxifeno } 60 \\
\quad(n=769)\end{array}$ & $\begin{array}{c}\text { Raloxifeno } 120 \\
(n=765)\end{array}$ \\
\hline $\begin{array}{l}\text { Incidencia } \\
\text { de fracturas }\end{array}$ & $15.5 \%$ & $2.6 \%$ & $21.2 \%$ & $14.7 \%$ & $10.7 \%$ \\
\hline $\begin{array}{l}\text { Reducción } \\
\text { de Riesgo } \\
\text { Absoluto* }\end{array}$ & -- & $1.9 \%$ & -- & $6.5 \%$ & $9.5 \%$ \\
\hline $\begin{array}{l}\text { NNT* }^{*} \\
\text { (IC 95\%) }\end{array}$ & -- & $\begin{array}{c}53 \\
(37 \text { a 111) }\end{array}$ & -- & $\begin{array}{c}15 \\
(9 a 47)\end{array}$ & $\begin{array}{c}10 \\
(8 \mathrm{a} 16)\end{array}$ \\
\hline $\begin{array}{l}\text { Riesgo } \\
\text { Relativo* } \\
\text { (IC 95\%) }\end{array}$ & -- & $\begin{array}{c}0.5 \\
(0.4-0.8)\end{array}$ & -- & $\begin{array}{c}0.7 \\
(0.5-0.9)\end{array}$ & $\begin{array}{c}0.5 \\
(0.4-0.7)\end{array}$ \\
\hline
\end{tabular}

Algunos datos fueron calculados por el comité editorial de Evidencia.

No hubo diferencias en la incidencia de fracturas no vertebrales en ninguno de los 3 grupos.

La densitometría ósea se elevó a los 36 meses, $2.1 \%$ y $2.6 \%$ en cuello femoral y columna con $60 \mathrm{mg}$ y 2.4 y $2.7 \%$ respectivamente con 120 $\mathrm{mg} / \mathrm{d}$. Hubo menor incidencia de cáncer de mama en las mujeres que recibieron raloxifeno (RR, 0.3; IC. 95\% 0.2-0.6). La incidenca de eventos tromboembólicos fue mayor en las pacientes tratadas con raloxifeno ( $1 \%$ vs. 0.3\% placebo; RR 3.1, IC 95\% 1.5-6.2). También hubo más síntomas menopáusicos (bochornos) en las tratadas con raloxifeno.

\section{Conclusiones}

En mujeres postmenopáusicas con osteoporosis el raloxifeno disminuye el riesgo de fracturas vertebrales e incrementa la densidad mineral ósea de raquis y cuello femoral

\section{COMENTARIO}

El presente estudio (MORE, del ingles Multiple Outcome of Raloxifene Evaluation) demuestra que las fracturas vertebrales detectadas clínicamente 0 por radiografías disminuyen en un 30-50\% luego de 36 meses de tratamiento con raloxifeno en mujeres menopáusicas. Estos resultados son comparables a los de otros medicamentos antirresortivos óseos como estrógenos o bisfosfonatos (alendronato). ${ }^{1} \mathrm{Al}$ igual que con éstos, la reducción de fracturas no está relacionada con el incremento de la densidad mineral, sugiriendo que hay otros factores que contribuyen a prevenir las fracturas. El incremento de la densidad mineral y el descenso de los marcadores bioquímicos de recambio óseo con raloxifeno sólo alcanzan la mitad de los valores observados en mujeres tratadas con alendronato. Por otra parte, al suspender alendronato, en pacientes tratadas por largo tiempo, la densidad mineral permanece estable 1-2 años. ${ }^{2}$ No se conocen estos datos para raloxifeno.

Este estudio también ha confirmado el hecho conocido de que una fractura ósea es el mejor predictor de una siguiente fractura. Las mujeres del grupo control con fracturas previas tuvieron un riesgo de fractura más de cuatro veces superior que aquellas sin fracturas preexistentes. Se demuestra, asismismo, que ningún tratamiento es capaz de inhibir en su totalidad la aparición de fracturas.

El raloxifeno es un modulador selectivo de los receptores estrogénicos (SERM)

\section{Dra. Ana María Galich}

Sección Osteopatías Metabólicas. Servicio de Endocrinología, Metabolismo y Medicina Nuclear. Hospital Italiano de Buenos Aires.

Referencias

1. Liberman U, Weiss SR, Broll J et al. Effect of oral alendronate on bone mineral density and the incidence of fractures in postmenop

3. Walsh BW, Kuller LH, Wild SP et al. Effects of Raloxifene on Serum Lipids and Coagulation Factors in Healthy Postmenopausal Women. JAMA. 1998;279:1445-1451.

4. Khovidhunkit W and Shoback D. Clinical Review. Clinical effects of raloxifene Hydrochloride in Women. Ann Intern Med. 1999;130:431-439.

. 